\title{
The Demographic Faultline Is a New Situational Factor for Team Management: The Effect of Leader Teamwork Behaviors on Support for Innovation
}

\author{
Dong Man $\mathrm{Na}^{1}$, Seong Hoon Park ${ }^{2}$, Won Jun Kwak ${ }^{3}$ \\ Received : September 5, 2018 Revised: September 30, 2018 Accepted: October 10, 2018
}

\begin{abstract}
An alternative method for team diversity studies is to examine demographic faultlines. A concept of demographic faultine enables us to better understand team dynamics with multidimensional diversity. This study suggests the demographic faultine as a new situational factorto influence the relationship between leader teamwork behaviors and a climate of support for innovation. When subgroups divided by demographic faultline are homogeneous within them and heterogeneous between them, the homogeneity may increase intimacy in each subgroup while the heterogeneity may increase exclusiveness between those subgroups. We argued that a leader could play an important role to build a cooperative relationship between faultline-based subgroups and highlight positive aspects of developing and maintaining subgroups in organizations. With a sample of 81 teams (558 employees), it was examined how leader teamwork behaviors would affect a team-level climate of support for innovation and how this relationship would be moderated by each team's demographic faultine (gender, age, and educational specialty). As predicted, it was found that there was a significant positive relationship between each leader's teamwork behaviors and each team's climate of support for innovation. In addition, this relationship was stronger for teams with strong faultline than with weak faultline. Our findings and their implications were further discussed.
\end{abstract}

Keywords: Group Faultlines, Diversity, Teamwork Behavior, Support for Innovation.

JEL Classification Code: D20, D23, M12, M54.

\section{Introduction}

Over the following decades, organizational innovation has become an essential focus in managerial and academic domains. While numerous companies are pursuing organizational innovation, unfortunately the variety and complex mechanism of factors that lead to innovation have been the hindrance to a successful innovation for most companies.

1 First Author. Senior Research Fellow, Korea Research Institute for Vocational Education \& Training, South Korea,

E-mail: shoutndm@krivet.re.kr

2 Second Author. Senior Research Fellow, Center for Social Entrepreneurship Studies, Seoul, South Korea,

E-mail: info@cses.re.kr

3 Corresponding Author. Professor, Department of Business Administration, Soongsil University, Seoul, South Korea [Postal Address: Kyoungsangkwan \#111, 369 Sangdo-Ro, Dongjak-Gu, Seoul, 06978, South Korea]

Tel: 82-10-6714-0727, E-mail: kwak@ssu.ac.kr
To date, a large number of researches about the antecedents of innovation were conducted. These factors range from the individual level to the team level, and to the organizational level (Jung, Chow, \& Wu, 2003). While each of these factors is indubitably relevant, individual level studies are limited to explain organizational innovation in an individual's creative behavior perspective (Mumford \& Gustafson, 1988). Organizational level studies suggest meaningful implications, but it can be easily criticized for its difficulty in practical applications. Consequently, West and Farr (1989) suggested that an organizational innovation is developed and originated by team level factors. In most researches, teams are considered critical factors in organizational innovation (Gibson \& Vermeulen, 2003). Moreover, according to West (2002), previous researchers examining innovation among teams have focused on three main themes: (a) the group task and the demands and opportunities that create innovation, (b) diversity among team members, (c) team integration to capitalize on their diverse knowledge and skills. In short, rather than 
concentrating on the innovative performance in the organizational perspective, team level studies emphasized more on focusing on the team's structure, work process, and climate. Particularly, the studies on climate that supports innovation as a kind of team climate for innovation have been conducted. (Howell \& Avolio, 1993; Jung et al., 2003; West, Borrill, Dawson, Brodbeck, Shapiro, \& Haward, 2003). These studies mostly regard a leader's role as an antecedent of climate that supports innovation. According to Howell and Avolio (1993) and Jung et al. (2003), transformational leadership has positive effects on climate that supports innovation. And other leadership characteristics, such as leadership clarity, also contribute to climate that supports innovation (West et al., 2003).

To present a coherent guide for leaders to innovative team climate, this paper focuses on teamwork behaviors that are required for a leader. As a team level study, these approaches provide significant assistance for managers by presenting a specific leader's role, which contributes to a successful innovation. Leader's individual behaviors, such as teamwork behaviors, are directly noticeable by other members (Tasa, Taggar, \& Seijts, 2007), so other members can be easily influenced.

Effectiveness of teamwork behavior on climate that supports innovation can be varied depending on attributes of the team. For example, when a leader ensures the whole member to attend group discussions, or when the leader's effort to encourage sharing ideas and settling conflicts does not fit the team's uniqueness and condition, a desirable outcome would be hard to follow after. As a condition that can influence the effectiveness of teamwork behavior, demographic composition of team is a critical variable as an attribute in the team.

There are generally two approaches on the study of demographic composition for team members. One considers the demographic similarity or heterogeneity of members, and the other reflects on the dynamics of forming subgroups based on demographic attributes. The former is a diversity approach, and the latter one, which was recently developed, is a faultine approach. Several researches on group diversity have only focused on the concept of heterogeneity, because these researches have considered diversity as "the degree to which there is dispersion of a particular attribute in a specified population" (Blau, 1977; Thatcher, Jehn, \& Zanutto, 2003). In methodology, operationalization of diversity has been often criticized, because these measures mostly focused on the distribution of members on one attribute at a time. (Thatcher et al., 2003; Zanutto, Bezrukova, \& Jehn, 2010).

Another alternative method used in diversity studies is to examine faultines as the alignment of multiple demographic attributes which can hypothetically subdivide a group
(Zanutto et al., 2010). The compositional dynamics of interacting with multiple attributes may affect group processes more than separate demographic characteristics can do (Lau \& Murnighan, 1998). Thus faultlines suggest more practical information than existing diversity measurements (Thatcher et al., 2003), and divulge the influences of subgroups that people formed in a team.

The concept of faultlines offers valuable information on when a team leader's behaviors can function more effectively. When a team divides into subgroups distinctly by demographic similarity, members will build intimacy and contribute psychological safety with each other. Due to the fact that members within a single subgroup tend to share common characteristics, people believe that within the subgroup other members will understand his or her standpoint and expect no criticism when expressing new ideas. To make a point, a subgroup divided by demographic similarity functions as a coalition. Therefore, when a team has a strong faultline, subgroup members are more likely to interact and share information (Lau \& Murnighan, 2005), and communications and sharing knowledge within subgroups are bound to flourish. In the situation where team members are asked to have discussions about team issues with each other, they are more likely to express their new ideas and opinions to other members. Therefore, this study will hypothesize that the effect of the team leader teamwork behaviors on climate that supports innovation is stronger with strong faultline teams than weak faultline teams. To test this hypothesis, three demographic attributes (gender, age, and educational specialty) from 81 teams in a single company will be calculated using group faultlines. Climate that supports innovation (Siegel \& Kaemmerer, 1978) will be focused as one sort of climate for innovation. Ina workgroup innovation theory (Anderson \& West, 1998), it is important to deal with the topic of team innovation as an outcome of team climate. Team climates also relate to team leader's behaviors because it mediates the relation between leader's behaviors and team performance (Pirola-Merlo, Hartel, Mann, \& Hirst, 2002; Smith-Jentsch, Salas, \& Brannick, 2001). Among the concepts of team climate for innovation (Anderson \& West, 1998), climate that supports innovation is a critical antecedent for innovative behaviors (Amabile \& Gryskiewicz, 1989; Bain, Mann, \& Pirola-Merlo, 2001; Jung et al., 2003; Scott \& Bruce, 1994).

This paper is organized as follows. The next few sections provide overviewon the relevant literature about team leader teamwork behaviors, climate that supports innovation, and group faultlines. Next, the methods used for overall research and our findings will be presented. The theoretical contribution and managerial implications will be discussed in the final. 


\section{Literature Review and Hypotheses}

\subsection{Team Leader Teamwork Behaviors and Support for Innovation}

West (1990) proposed that team innovation can be encouraged in a team climate where creative ideas and attempts are supported. This innovative team climate is called asclimate that supports innovation. Climate that supports innovation is defined as "the expectation, approval and practical support of attempts to introduce new and improved ways of doing things in the work environment" (West, 1990, p.38). Specifically, climate that supports innovation is innovation-related climate of team members such as assisting or cooperating with each other in order to develop new answers and ideas. And it is also a team's climate such as sharing resources, providing practical support, or monitoring process and performance for improvement (Anderson \& West, 1998).

This type of climate that supports innovation is a vital antecedent for team innovation. (Amabile \& Gryskiewicz, 1989; Bain et al., 2001; Jung et al., 2003; Scott \& Bruce, 1994). According to Amabile and Grykiewicz (1989), providing an exceedingly creative work environment requires support and encouragement at workgroup level. Furthermore, Amabile and Conti (1999) stated encouragement and support for workgroup enhance creativity, even in the face of organizational downsizing, a dire situation when organizational innovation is considerably unfavorable. In their analysis on research and development teams, Bain et al. (2001) also held that among the kinds of climate pertinent to team innovation, climate that supports innovation as the most influential antecedent towards innovative behavior such as sparking new ideas.

Therefore, defining the critical antecedents of climate that supports innovation bears heavy significance. Many relevant studies highlight a leader's behavior as a key antecedent preceding climate that supports innovation. Previous studies claim that higher LMX (leader-member exchange) promises higher the supportive climate for innovation (Scott \& Bruce, 1994). Climate that supports innovation also improves when the team leader displays as an effective facilitator (PirolaMerlo et al., 2002), or when he or she shows strong transformational leadership (Jung et al., 2003; Pirola-Merlo et al., 2002). Moreover, these researches empirically prove that climate that supports innovation mediates the relationship between the leader's behavior and team innovation.

This study especially focuses on leader teamwork behaviors, which is capable of being specifically perceived by team members. Teamwork behaviors are the typology of knowledge, skills, and abilities (KSAs) contributing team performance (Stevens \& Campion, 1994; Tasa et al., 2007) and team maintenance (Cannon-Bowers, Tannenbaum, Salas, \& Volpe, 1995). These behaviors represent observable actions and verbal communication, which are displayed during interactions between team members to ensure a successful collective action (Morgan, Salas, \& Glickman, 1993).

Teamwork behavior is a multifaceted concept (Rousseau, Aube, \& Savoie, 2006). Rosseau et al. (2006) reviewed 29 teamwork behavior frameworks, which previous scholars researched for the past 20 years. Therefore, management of team maintenance and regulation of team performance were proposed as two mechanisms to compose teamwork behavior. Management of team maintenance is a set of activities managing interpersonal issues that endanger the maintenance of the team (Rousseau et al., 2006). Management of team maintenance is comprised of integrative conflict management. Integrative conflict management refers to the integration of members' interests while resolving conflicts among members (Janssen, Van de Vliert, \& Veenstra, 1999). When team members accomplish collective tasks, conflicts are inevitable, since their backgrounds and values are different (Stevens \& Campion, 1994). When they are not managed adequately by team members and when they persist within team, the conflict would be harmful for the team (Tjosvold, 1998). Consequently, integrative conflict management is an essential teamwork behavior for a leader to maintain the team.

The classification of the dimensions of teamwork behaviors in regard to the regulation of team performance is based on the action regulation theory (Rousseau et al., 2006). As stated in this theory, individuals attain high performance when there has been work-related regulation (Arrow, Poole, Henry, Wheelan, \& Moreland, 2004). This regulation to enhance team's achievement is consists of preparation, execution, evaluation, and adjustment function; which all four can manage entire work processes of the team members (Rousseau et al., 2006).

Several researches on teamwork behaviors assume selfmanaged team when analyzing (e.g., Tasa et al., 2007). However, in most cases, it is rare having the entire team member to perform as a manager. Therefore, teamwork behaviors of a leader are critical in common teams. For instance, specifying team goals, setting deadlines, assessing performance and giving feedback, managing integrative conflict management are actually a role given to a leader and not to the whole members.

While variables related to innovation of the team, such as climate that supports innovation, are team level variables, measuring in individual level is inevitable when studying 
teamwork behaviors of the members. Therefore, researches assuming a self-managed team measure teamwork behaviors in an individual level, and create a team level variable with additive aggregation (e.g., Tasa et al., 2007). However, teamwork behaviors of a leader can be measured in a team level, and it is possible to be applied as a team level variable.

As a consequence, we focus on teamwork behaviors of a leader as an antecedent of climate that supports innovation. Teamwork behaviors of a leader can directly influence the team climate. For example, effective team leader may try to minimize the impact of negative events that led to negative climate (Pirola-Merlo et al., 2002), and these negative climate and mood may inhibit to help and cooperate behaviors for effective team performance (George, 1991). Whereas, we argue that leader teamwork behaviors would make team members to support each other for innovation. For example, when a team leader promotes activities such as coordinating activities, or managing collective problem solving, a team member could observe that other members act cooperatively with each other, and then team member's perceived climate that supports innovation may increase. Thus, underlying the mechanism of our conceptual model is that team leader teamwork behaviors would make team members to support each other for team innovation.

Team leader teamwork behaviors may have positive influence on climate that supports innovation in various ways. Firstly, teamwork behaviors for managing team maintenance enable team members to resolve the conflict collectively (Rousseau et al., 2006). Therefore, a leader could calm down team members who are in conflict with teamwork behaviors, and address conflict immediately by raising it for group discussion (Tasa et al., 2007). This collective conflict resolution would be continued until the solution is discovered (Spreitzer, Cohen, \& Ledford, 1999), and in order to find the answer, members will work through a process taking other opinions into consideration (Janssen et al., 1999). Therefore, sharing and accepting various perspectives result in good team decision (Alper, Tjosvold, \& Law, 2000). Thus, the integrative conflict resolution would enable team members to work together and share different perspectives with each other, and through this process, climate that supports innovation would rise.

Secondly, in terms of the regulation of team performance, teamwork behaviors consist of setting time deadlines for achieving tasks, reminding other team members of the team's goal (Tasa et al., 2007). Leaders who perform these behaviors to improve the team performance will provide constructive feedback (Cannon-Bowers et al., 1995), and this feedback presents work related advice, suggestions, guidance, instructions to team members (Rousseau et al., 2006). And these regulations of team performance (e.g. managing goal and work process) enable team members to monitor their performance continuously in order to achieve the highest standards (Anderson \& West, 1998). Moreover, teamwork behaviors ensure every team member's participation in group discussion and steer them towards ontopic conversation (Tasa et al., 2007). Through this discussion, leaders who perform these behaviors increase team interaction. More exactly, leaders can drive team members to collaborate with each other with coordination, cooperation, information exchange. According to Taggar and Seijts (2003), during team interaction, team members share resources not only about their own competencies, but also other team members' capabilities. Therefore, team interaction increases climate that supports innovation (Anderson \& West, 1998).

Summing up, in various ways, leader teamwork behaviors would have positive effects on climate that supports innovation. On the basis of this discussion, we proposed the following hypothesis:

H1: Team leader teamwork behaviors will have positive effect on climate that supports innovation.

\subsection{Group Faultline}

Faultlines can be defined as hypothetical dividing lines that may split a group into subgroups based on one or more attributes (Lau \& Murnighan, 1998; Thatcher et al., 2003). Depending on the similarity and salience of group members' attributes, groups may have many potential faultlines, each of which may activate the potential for particular subgroupings (Lau \& Murnighan, 1998). For instance, demographic faultines exist when a group contains distinct subgroups that differ on multiple demographic features, including age, race, gender, educational level, educational specialty, and so on. And group members who share similar demographic characteristics align together creating homogeneous subgroups. For example, a group consisting of two 30-year-old female doctors and two 20-year-old male college graduates would possess a substantial faultline, with two subgroups differing distinctly on three demographic dimensions, such as age, gender, and educational level.

Generally, workgroups consist of more than four people differing from the previous example and may form subgroups based on similarity and salience with combination of more various attributes (e.g., age, race, tenure, educational level, educational background, functional area, and even belief or value). Therefore, the concept of faultlines is important to understand the effects of demographic composition of workgroups.

According to Thatcher et al. (2003), the concept of faultlines is based on self-categorization theory (Turner 
1982), social identification theory (Tajfel, 1978), the similarity-attraction paradigm (Byrne, 1971), and coalition theory (Murnighan \& Brass, 1991). Self-categorization theory posits that group members classify themselves and others into familiar categories, and these categorizations are also used in defining an individual social identity (Thatcher et al., 2003; Turner, 1987). Social identity means an individual's knowledge that one belongs to certain social groups and has the emotions and values that linked with that social group or category (Turner, 1982). In similarityattraction paradigm, group members may be attracted to others who are similar to themselves (Byrne, 1971). And similarity between individuals may lead to more frequent communication and a desire to remain in the group (Lincoln \& Miller, 1979). In most case, demographic attributes are important factors for individuals in determining the similarity. These theories provide informative explanations how demographic characteristics are used to create subgroups. To conclude, demographic faultlines can only exist when individuals identify with certain subgroups and categorize themselves as belonging to particular groups (Thatcher et al., 2003).

Meanwhile, coalition theory can help us better understand how the dynamics in subgroups influences team process and outcome. Coalitions are subsets of members who often pool their resources and unite as a single voice (Murnighan \& Brass, 1991; Thatcher et al., 2003). According to coalition theory, coalitions within a team tend to be derived from simultaneous considering similarities in demographic backgrounds, similarity of titles, or prior experience (Eisenhardt \& Bourgeois, 1988). Thus, in the terms of coalition, group faultlines can provide explanations for the role of subgroups whose members share their knowledge and resources, and cooperate with each other beyond the processes of categorization, identification, and similarityattraction. This differentiated background of faultlines makes it possible to investigate the effects of demographic diversity on outcomes more clearly, in contrast to the prior researches on diversity that have shown mixed results on the relationship between diversity and outcome (Thatcher et al., 2003).

\subsection{ModeratingRole of Group Faultlines}

The effectiveness of leader teamwork behaviors on team climate that members assist or cooperate with each other in order to develop new answers and ideas may depend on the existence of subgroups as coalitions. In other words, group faultines may have moderating effects on the relationship between team leader teamwork behaviors and support for innovation.
As in the previous review, team members categorize themselves from others based on their demography and establish his or her social identity. Also, team members are attracted to other members with similar demographic attributes and then they communicate more frequently. Finally, the members form subgroups. This subgroup are clearly divided by homogeneity of demographic attributes, and distinguished from other groups by heterogeneity of demographic attributes.

A cohort can be provided by a subgroup. An individual expects the members of his or her subgroup to be more agreeable on his opinion than those who are not in the subgroup. The presence of other members in a team who are understanding or share a given viewpoint, is helpful for an individual to express his other opinion and for it to be taken into account in the team's decision making (Stasser, Taylor, \& Hanna, 1989; Wittenbaum \& Stasser, 1996). Thus, when faultines exist in a team, individual knowledge can spread out to the entire team, and as a consequence, a collaborative atmosphere is present.

Meanwhile, there are also the negative aspects of strong faultines. There are enough possibilities that members of strong subgroups are unlikely to relate to members of other subgroups. Having support from their own subgroup, team members are more likely to follow the opinions of their subgroup members thoughtlessly (Abrams, Wetherell, Cochrane, Hogg, \& Turner, 1990; Mullen, 1991), whereas they are less open to opinions and perspectives expressed from outside the subgroup. Consequently, interaction between subgroups is reduced, and impasse impedes conflicts from being resolved (Lau \& Murnighan, 1998). However, we will exclude a situation with extremely strong faultline from the discussion, since the faultine strength is likely to range from moderately weak to moderately strong in actual setting. In most cases, there is no workgroup that has completed homogenous subgroup splits or extremely strong faultline (Thatcher et al., 2003). Therefore, even between subgroups divided by the demographic faultline, some homogeneity exists, and it means feasible possibility of interaction between the subgroups also exists. Gibson and Vermeulen (2003) found that teams that had moderately strong demographic subgroups as 'a healthy divide' reported more learning behaviors. Having such subgroup members, who share common sources of identity (such as gender and educational background), it may make one feel more secure about her own ideas (Gibson \& Vermeulen, 2003). In short, the exclusiveness based on heterogeneity between subgroups could be weakened by teamwork behaviors.

To first discuss situations with strong and weak faultlines, we assumed that team members are likely to categorize members and form subgroups according to their 
demographic similarity. The situation with strong demographic faultline can be defined as follows. First, individuals confirm their homogeneous subgroup as a coalition. In teams with a strong faultine, members within a subgroup tend to support each other based on commonly shared attitudes toward issues (Murnighan \& Brass, 1991), to have similar viewpoints (e.g., Walsh, 1988), and to unite as a single voice (Murnighan \& Brass, 1991; Thatcher et al., 2003). Consequently, when the members assure that they have fellows, who will completely understand with the same perspective, team members show active involvement providing ideas without hesitation.

Secondly, in a similarity-attraction paradigm, members, who belong in a same subgroup, feel a sense of intimacy with each other. There are tendencies to help each other, and low interpersonal conflict. As a consequence, the possibility to have negative influence, such as reducing interaction between members and impasse preventing problem from solving, from the interpersonal conflict is very low.

On the contrast, team with low demographic faultline can be defined as a confusing situation, which is hard for members to determine their own subgroup.

The teamwork behaviors of leaders have following advantages in a strong demographic faultline. First, the presence of another person in a team, who understands or shares a given viewpoint, decreases the anxiety for the member to express new ideas and opinions, which ultimately motivates the team members to be more active. In a situation with strong faultline, the effect of leader teamwork behaviors, such as making the team members to discuss issues and combine ideas, can be enhanced. Therefore, leader teamwork behaviors drive the team members to provide practical support for new ideas to each other and strengthen the team to search fresh ways of looking at a problem.

Secondly, in a strong faultine situation, subgroup members are intimately linked to each other, and cooperative climate exists. In this situation, the effect of leader teamwork behaviors, which manages team conflicts, can be developed. In a team with strong faultine, possibility to build up a serious conflict within a subgroup is likely to be low. Even if a conflict break out, since the members are willing to cooperate with each other, the problem is likely to be solved. Leaders in this situation can effectively manage interpersonal conflict through teamwork behaviors, which will have more influence on climate that supports innovation. Furthermore, the leader could save time for managing interpersonal conflict, thereby, focusing more on goal attainments. And he or she can move team members to take more time needed to develop new ideas (Anderson \&
West, 1998). Based on these arguments, we proposed the following hypothesis:

H2: Faultlines will moderate the effect of a team leader teamwork behaviors on support for innovation, such that leader teamwork behaviors are more effective for teams with strong faultline than with weak faultline.

Figure 1 presents our conceptual model. In the previous researches on diversity, diversity variables often have been considered as independent variables. However, in this model, we treat faultlines as a moderating variable, because diversity and faultlines tend to have different effects. Specifically, demographic diversity may be a source of task conflict, interpersonal conflict, and creativity; faultlines may also contribute to various forms of intragroup conflict, but they are likely to have much less impact on creativity (Lau \& Murnighan, 1998). Thus, we developed a model with moderating effects of faultlines.

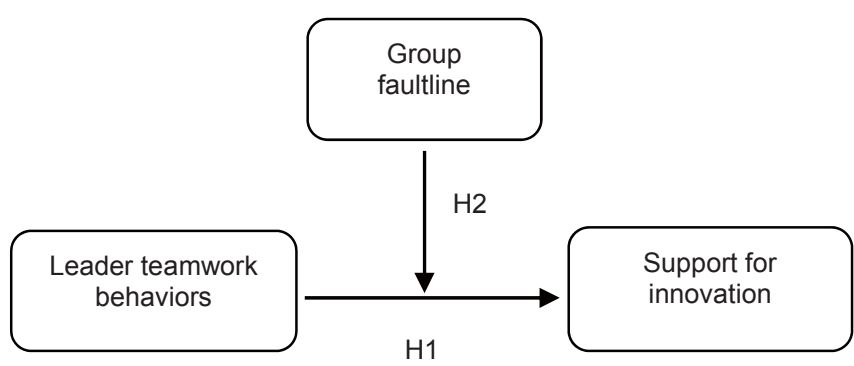

Figure 1: Research Model

\section{Methodology}

\subsection{Data and Sample}

This field study was conducted on 1,106 individuals in 101 teams in a single company. This company provides heating service. We collected data from a single company, because samples from a single company can be free from various factors which influence team effectiveness (e.g., leadership style, HR practices, and so on). Therefore, we obtained controlled effects of various factors beyond team level. Questionnaires were distributed to all employees and 563 questionnaires were returned, which is equivalent to a response rate of $50.9 \%$. Among the questionnaires obtained from the employees, over two-thirds of the total - 58 teams out of 101 teams- were selected for data analysis.

To reflect the actual workgroup, we redevised 58 teams into 158 groups by task type. Then, we sorted the groups of 
4 to16 members out from 158 groups, which the entire member of the group had completely responded to all questionnaires. Consequently, a total of 81 groups of the 158 groups were selected for this study.

The average age of the respondents was 36 , and $90 \%$ of them were male. Respondents majored in three different disciplines, such as social sciences or humanities (18.4\%), natural sciences or engineering $(70 \%)$, and the others $(11.6 \%)$.

The team's information about demographic composition, which includes age, gender, educational background, and team size, was obtained from the personnel department of the company.

\subsection{Measures}

We measured climate that supports innovation with support for innovation measurements from Anderson and West (1998). Anderson and West suggested these items by selecting four items from Siegel and Kaemmerer's (1978) climate for innovation measurements and developed four new items. Sample items were 'This team is always moving toward the development of new answers', 'Assistance in developing new ideas is readily available' (1=not at all; $7=$ very much so). The coefficient alpha for the scale was .996.

To measure leader teamwork behaviors, we adopted the 12 items from Tasa et al. (2007). These items were selected from a 46-item behavioral observation scale (BOS) developed by Tagga and Brown (2001). Tasa et al. (2007) assembled the 12-item based on a consideration that those items represented the interpersonal and management KSAs of Stevens and Campion's (1994) typology. These 12 items of Tasa et al. (2007) were peer-rated items. Thus we converted 'my team members' to 'my team leader'. Sample items were 'Set time deadline for achieving tasks', 'Take steps to ensure everyone participates in group discussions' ( $1=$ not at all; $7=$ very much so). The coefficient alpha for the scale was .994 .

To measure faultlines, we calculated 'group faultline score' by multiplying faultline strength by distance and followed the methodology set measuring faultines, which Thatcher et al. (2003) and Zanutto et al. (2010) proposed. While dividing the group into three or more subgroups, we considered only faultine that splits a group into two subgroups. These are the most common split type in groups of small to moderate size, and the most important because they are stronger (Lau \& Murnighan, 1998) and have more impact on members' interaction than those splits into three or more subgroups (Zanutto et al., 2010). Faultlines were measured by combining three demographic characteristics (age, gender, and educational specialty), since we value these demographic characteristics as critical factors for group members to form subgroups in our dataset.

To examine how faultline can help us to understand the effects of diversity on groups, we should understand the measurements and aspects of faultlines. There are two aspects of faultlines; faultline strength and distance. Faultline strength captures how many demographic attributes align within a group or, in other words, how cleanly a group may split into two homogeneous subgroups (meaningful about similarities). Faultline distance, however, reflects the extent to which subgroups diverge as a result of accumulated differences across aligned subgroups (meaningful about differences) (Zanutto et al., 2010).

An example of a strong faultine group would be a group of four members that consists of two men around the age of 40 , who majored in engineering, and two women around the age of 30 who majored in accounting. In this case, the faultine is strong within the group because there are two homogeneous subgroups based on their gender, age, and educational specialty. An example of a weak faultline group would be a group of four members consisting of one woman in her 20s, who majored in history, one woman in her 40s, who majored in accounting, one man in his 30 s, who majored in law, and one man in his 50s, who majored in engineering. In this group, subgroups may form around the categories of gender, age, or educational specialty. But, the subgroups would not be as strong as in the former example because these subgroups only have similarity on one dimension.

We take another example of groups that have same faultline strength. One group consists of two 20-year-old female engineers and two 30-year-old male accountants, and the other group consists of two 20-year-old female engineers and two 50-year-old male accountants. Both groups have same faultline strength $(F a u=1.0)$. However, they have different faultline distance. Thus, the former group has a shorter faultline distance than the latter one. According to Arsenault (2004) and Zanutto et al. (2010), group members who are more distant in age would have different interests and would find it harder to interact with members of opposing subgroup. Thus, while groups have same faultline strength, strength does not consider how one subgroup is apart from other subgroup (Zanutto et al., 2010).

Majority of researches about faultines have focused on only the concept of faultline strength which is the extent of demographic alignment across members within a group (e.g., Lau \& Murnighan, 1998; Thatcher et al., 2003) (Zanutto et al., 2010). However, another important aspect of faultlines that is defined as differences or distance between aligned subgroups has been ignored. Thus, in this study, we simultaneously consider both faultline strength and distance.

First, we measured faultline strength ( Fau) as the proportion of total variation in overall group characteristics 
explained by the strongest group split.Fau is always larger than zero and less than or equal toone, with larger values indicating greater faultline strength. Calculating Fau can be viewedas a two-step process. The first step is to calculate:

$$
\operatorname{Fau}_{g}=\left[\frac{\sum_{j=1}^{p} \sum_{k=1}^{2} n_{k}^{g}\left(\bar{x}_{\cdot j k}-\bar{x}_{. j}\right)^{2}}{\sum_{j=1}^{p} \sum_{k=1}^{2} \sum_{i=1}^{n_{k}^{g}}\left(\bar{x}_{i j k}-\bar{x}_{. j}\right)^{2}}\right] \mathrm{g}=1,2,3, \ldots \mathrm{S},
$$

where $x_{i j k}$ is the value of the $j^{\text {th }}$ characteristic of the $i^{\text {th }}$ member of subgroup $k, \bar{x}_{. j}$. is theoverall group mean of characteristic $j, \bar{x}_{\cdot j k}$ is the mean of characteristic $j$ in subgroup $k$, and $n_{k}^{g}$ is the number of members in $k^{\text {th }}$ subgroup $(k=1,2)$ under split $g$. The second step isto calculate the maximum value of $\mathrm{Fau}_{g}$ over all possible splits $g=1,2,3, \ldots S$ (or, to avoid subgroups of size one, we can maximize over all splits where each subgroup contains at least two members).

This Fau measure can be calculated using both continuous and categorical variables. To include categorical variables, such as gender or educational specialty in this study, in the Fau measure, we have to recode them into a series of dummy variables. A categorical variable with $\mathrm{c}$ categories should be recoded as c dummy variables (Jobson, 1992). Then, we rescaled the continuous variables and the dummy variables so that they can be reasonably combined into one distance measure (Thatcher et al., 2003; Zanutto et al., 2010).

To measure faultline distance, we used a distance score which measures how far apart the two subgroups are on demographic characteristics. Faultline distance captures the degree of difference between two subgroups formed as a result of the strongest possible group split (Zanutto et al., 2010). The most obvious case where faultine distance is useful is when a group splits cleanly along all characteristics $(F a u=1)$, and faultline distance indicates how far apart the two subgroups are, thereby differentiating among groups with $F a u=1$. More generally, faultline distance helps us to differentiate among groups with the same Fau (not just Fau=1). Thus, we can distinguish between groups with the same Fau measure but different distance and with the same distance measure but different Fau by faultline distance.

Our faultine distance measure is adapted from multivariate statistical cluster analysis (e.g., Jobson, 1992; Morrison, 1967; Sharma, 1996) and is calculated as the distance between subgroup centroids (the Euclidean distance between the two sets of averages):

$$
D_{g}=\sqrt{\sum_{j=1}^{p}\left(\bar{x}_{j 1}-\bar{x}_{. j 2}\right)^{2}}
$$

where the centroid (vector of means of each variable) for subgroup1 $=\left(\mathrm{X}_{11}, \mathrm{X} \cdot 21, \mathrm{X} \cdot 31, \ldots, \mathrm{X} \cdot \mathrm{p} 1\right)$ and the centroid for group $2=(\mathrm{X} \cdot 12, \mathrm{X} \cdot 22, \mathrm{X} \cdot 32, \ldots, \mathrm{X} \cdot \mathrm{p} 2)$. Faultline distance can take on values between 0 and $\infty$, with larger values indicating larger distance between the resulting subgroups (Zanutto et al., 2010).

Although faultline strength (Fau) and faultline distance (D) provide separate information about potential faultines and can be used as separate variables in an analysis, Zanutto et al. (2010) suggested that only when the two aspects of faultlines are considered simultaneously (as with a multiplier form, or interaction), we see the true effects of faultlines in groups. They gave a concrete example as follows. An alignment of members (faultline strength) induces awareness of membership into separate and distinct subgroups. However, faultline distance moderates this relationship by escalating more antagonistic subgroup interactions in groups with large distance, in which the members of one subgroup are extremely different from members of another subgroup (emphasis on differences). By multiplying the scores of strength and distance in the interaction term, we can consider all information. This extension of faultline framework provides a more comprehensive view of diversity and demographic alignment than presented by previous works.

We entirely agree with Zanutto and her colleagues (2010) about the necessity of considering faultline strength and faultline distance simultaneously. Hence, in this study, we use group faultline score by multiplying faultline strength and distance score.

$$
\text { Group faultline score }=\mathrm{Fau}_{g} \times D_{g}
$$

Finally, we controlled team size and task interdependence. We included team size in our model, because team size may influence interaction, conflict, and sharing resource. Task interdependence may also affect climate that supports innovation. Jehn (1995) found lower level of conflict in groups with low levels of interdependence than in highly interdependence group. This is similar to the results in Thatcher et al.'s (2003), which posited that limited interaction across subgroups creates less opportunity for conflict. Task interdependence was measured by 5 -item of Van der Vegt and Janssen (2003). Sample items were 'I need information and advice from my colleagues to perform well in my job', 'I have a one-person job: it is not necessary for me to coordinate or cooperate with others' (1=completely disagree; $7=$ completely agree). The coefficient alpha for the scale was .988. To reduce multicollinearity, we centered all variables following Aiken and West's (1991) advice. 


\section{Results}

Descriptive statistics, correlations, and reliability are reported in Table 1. The correlations indicate that leader teamwork behaviors are significantly related to climate that supports innovation.

Table 1: Means, Standard Deviations, Correlations, and Alphas ${ }^{a}$

\begin{tabular}{|c|c|c|c|c|c|c|}
\hline Variables & Mean & S.d & 1 & 2 & 3 & 4 \\
\hline 1. Support for innovation & 5.32 & \begin{tabular}{|l|}
0.56 \\
\end{tabular} & \begin{tabular}{|l}
$(.99)$ \\
\end{tabular} & & & \\
\hline 2. Team size & 6.88 & 2.86 & -.15 & $(-)$ & & \\
\hline 3. Task interdepedence & 5.12 & 0.48 & $.36^{* *}$ & .10 & $(.99)$ & \\
\hline 4. Leader teamwork behaviors & 5.29 & 0.58 & $.73^{*+*}$ & -.06 & .20 & $(.99)$ \\
\hline 5. Faultline score & 0.02 & 0.07 & -.01 & .02 & -.10 & .05 \\
\hline
\end{tabular}

To test the existence of common method bias, we conducted Harman's single factor test (Podsakoff \& Organ, 1986). For this test, we elaborated exploratory factor analysis with all the items. Then 3 factors emerged from an unrotated factor solution and the first factor explained only $33.7 \%$ of the variance in the variables. Thus, according to Podsakoff and Organ (1986), we concluded that the possibility of existence of common method variance were low.

To test hypotheses, a regression analysis was conducted. Since the maximum value of VIF is 8.805 in model 3 , there was no problem of multicollinearity. In Table 2, model 1 represents the effects of control variables, team size and task interdependence on climate that supports innovation. Model 2 shows the main effect of independent variable. There is a significant relationship between leader teamwork behaviors and climate that supports innovation $(\beta=.676$, $\mathrm{p}<.001)$. Therefore, hypothesis 1 is supported strongly.

Table 2: Results of Regression Analyses

\begin{tabular}{|c|c|c|c|}
\hline \multirow{2}{*}{ Variables } & \multicolumn{3}{|c|}{ Support for innovation } \\
\hline & Model 1 & Model 2 & Model 3 \\
\hline \multicolumn{4}{|l|}{ Controls } \\
\hline Team size & $-.18^{\dagger}$ & $-.13^{\dagger}$ & -.11 \\
\hline Task interdependence & $.38^{n \times n}$ & $.24^{\pi N x}$ & $.24^{N \pi \times x}$ \\
\hline \multicolumn{4}{|l|}{ Independent variables } \\
\hline Leader teamwork behaviors & & $.68^{\mathrm{nnn}}$ & $.63^{\mathrm{nkm}}$ \\
\hline \multicolumn{4}{|l|}{ Moderator } \\
\hline Faultline score & & & $-1.65^{\prime \prime}$ \\
\hline $\begin{array}{l}\text { Leader teamwork behaviors } \\
{ }^{*} \text { Faultline score }\end{array}$ & & & $1.65^{n}$ \\
\hline Adjusted $\mathrm{R}^{2}$ & .14 & .58 & .60 \\
\hline Overall F & $7.62^{n+m}$ & $38.41^{\mathrm{N*}}$ & $24.58^{n \times m}$ \\
\hline
\end{tabular}

Note. ${ }^{a} \mathrm{n}=87$ teams (558employees). Standardized regression coefficients are shown.

${ }^{\dagger} p<.1 ;{ }^{*} p<0.05 ;{ }^{* *} p<0.01 ;{ }^{* * *} p<0.001$
Model 3 presentsthe moderating effect of faultlines. The moderating effect of faultlines is significant while independent variable and moderating variable are controlled $(\beta=1.646, p<.05)$. Thus, hypothesis 2 is supported. To interpret this moderating effect, we re-arrange multiple regression equation into simple regressions, given conditional values of faultline score (mean +1 s.d.; mean 1 s.d.; cf. Aiken \& West, 1991).

Figure 2 shows the moderating effect of faultlines on relationship between leader teamwork behaviors and climate that supports innovation. With strong faultlines, the effect of leader teamwork behaviors on climate that supports innovation is amplified. Finally, we conclude that teamwork behavior from a leader is more effective in strong faultline teams than weak faultline teams.

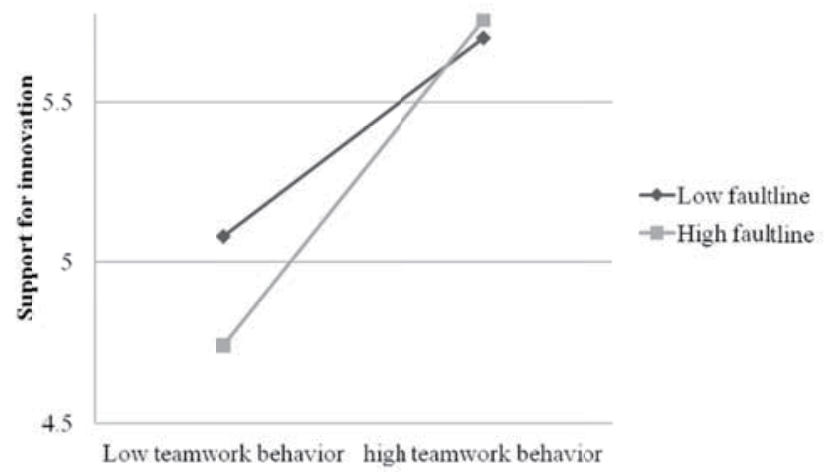

Figure 2: Interaction between Leader Teamwork Behaviors and Group Faultlines

As a conclusion, leader teamwork behaviors has a positive relationship with climate that supports innovation (hypothesis 1), and group faultlines moderate the relationship between leader teamwork behaviors and climate that supports innovation (hypothesis 2).

\section{Discussion and Conclusions}

In this study, we found empirical evidence that team leader teamwork behaviors have positive influence on supportive climate for innovation. And these influences are more effective under situations of strong faultline teams than weak faultline teams. These empirical findings have several contributions to the literature on demographic faultlines and teamwork behaviors.

First, while most previous researches about faultlines only focused on the concept of faultline strength, we simultaneously considered both concepts of faultline 
strength and distance in this study. Conceptually, faultline strength captures how many demographic attributes align within a group or, in other words, how cleanly a group may split into two homogeneous subgroups. Faultine distance, however, reflects the extent to which subgroups diverge as a result of accumulated differences across aligned subgroups (Zanutto et al., 2010). Zanutto et al. (2010) also suggested that only when the two aspects of faultlines are considered simultaneously, all information can be considered. Thus, our study reflects the characteristics of the actual faultline.

In our study, faultlines were measured by combining three demographic characteristics (age, gender, and educational specialty), since we value these demographic characteristics as critical factors for group members to form subgroups. It is up to only researcher's discretion which demographic attributes should be included for measuring faultlines. However, the combinations of attributes included in the calculation of faultline depend on culture, characteristics of the organization, team compositions, and so on. Thus, in future researches, we need to understand how people divide demographic subgroups and empirically verify which attributes should be included for measuring demographic faultline. Additionally, forming subgroups in a team, members may consider not only demographics in surface-level but also deep-level attributes. Thus, to measure substantial faultlines, it should be important in future researches to consider deep-level attributes, such as attitudes, knowledge, values, and so on. These efforts discovering the faultine factors will lead us to better understand actual faultlines existing in a team.

Second, we obtained significant results from quantitative faultlines in field settings. Despite the theoretical appeal of the faultline concept, there are a few empirical studies on it (Li \& Hambrick, 2005). Researchers have often applied the concept to qualitative studies (e.g., Dyck \& Starke, 1999; Ely \& Thomas, 2001). However, the measurement and application of faultlines in empirical quantitative research has been relatively limited, since there have been some challenges associated with a partially fitting conceptualization of faultlines, an ambiguity of faultline operationalization, and a lack of reliable method for quantifying such group splits (Trezzini, 2006).

In studying faultlines, the measurement of faultlines is laborious since a researcher can only calculate faultlines by examining every pair of members on every demographic dimension, in order to search distinctively different patterns. Even if faultline is calculated, it is unlikely that field settings will yield meaningful results. Consequently, the results of the research conducted to date have been insufficient to be consolidated and generalized (Li \& Hambrick, 2005). In spite of these difficulties, to measure faultlines, we examined every pair of members on essential demographic dimensions, such as age, gender, and educational specialty. Then, faultlines were measured by combining these demographic characteristics. In our study, these faultlines obviously come into play as a moderator of the positive relationship between leader teamwork behaviors and support for innovation.

Finally, we also provide a managerial implication for team leaders. More exactly, we suggest the demographic faultline, which should be considered as a new situational factor. The team faultline dividing a team into two subgroups is ambivalent towards team dynamics. It implies not only the existence of members who are similar to me, but also the existence of other members who are heterogeneous to me. According to coalition theory, coalitions within a team tend to be derived from simultaneous considering similarities in demographic backgrounds, similarity of titles, or prior experience (Eisenhardt \& Bourgeois, 1988). As we have seen, coalitions are subsets of members who often pool their resources and unite as a single voice (Murnighan \& Brass, 1991; Thatcher et al., 2003). The presence of coalitions in a team who is understanding or shares agiven viewpoint is helpful for an individual to express his other opinion (Stasser, Taylor, \& Hanna, 1989; Wittenbaum\& Stasser, 1996). However, there is a certain possibility that members are unlikely to interact with members outside coalition. To be exact, team members are more likely to follow the opinions of their subgroup members without much thought (Abrams et al., 1990; Mullen, 1991), whereas they are less open to opinions and perspectives expressed from outside the subgroup. Consequently, interaction between subgroups can be reduced, and impasse will prevent conflicts from being resolved. These negative aspects of strong faultlines are shown in Figure 2. In Figure 2, the degree of supportive climate for innovation with strong faultlines is lower than that with weak faultlines. However, the effect of leader teamwork behaviors on supportive climate for innovation is amplified by strong faultlines.

As discussed above, we excluded a situation with extremely strong faultline from the discussion. Generally, since homogeneity between members in different subgroup exists, there are sufficient possibilities for interaction between subgroups. As a consequence, a leader can play an important role as a bridge between subgroups in order to reduce the exclusiveness and distrust, and can activate positive aspects of the subgroups. Thus, our findings provide practical implications by considering not the types of leadership but the new specific actions, bridging between strong subgroups. 


\section{References}

Abrams, D., Wetherell, M., Cochrane, S., Hogg, M. A., \& Turner, J. C. (1990). Knowing what to think by knowing who you are: Self-categorization and the nature of norm formation, conformity and group polarization. British Journal of Social Psychology, 29, 97-119.

Aiken, L. S., \& West, S. G. (1991). Multiple regression: Testing and interpreting interactions. Thousand Oaks, CA: Sage.

Alper, S., Tjosvold, D., \& Law, K. S. (2000). Conflict management, efficacy, and performance in organizational teams. Personnel Psychology, 53, 625-642.

Amabile, T. M., \& Conti, R. (1999). Changes in the work environment for creativity during downsizing. Academy of Management Journal, 42(6), 630-640.

Amabile, T., \& Gryskiewicz, S. (1989). The creative environment scales: The Work Environment Inventory. Creativity Research Journal, 2, 231-254.

Anderson, N. R., \& West, M. A. (1998). Measuring climate for workgroup innovation: Development and validation of the team climate inventory. Journal of Organizational Behavior, 19, 235-258.

Arsenault, P. M. (2004). Validating generational differences: A legitimate diversity and leadership issue. Leadership and Organizational Development Journal, 25, 124-141.

Arrow, H., Poole, M. S., Henry, K. B., Wheelan, S., \& Moreland, R. (2004). Time, change, and development: The temporal perspective on groups. Small Group Research, 35, 73-105.

Bain, P. G., Mann, L., \& Pirola-Merlo, A. (2001). The innovative imperative: The relationships between team climate, innovation, and performance in research and development teams. Small Group Research, 32(1), 55-73.

Blau, P. M. (1977). Inequality and Composition: A Primitive Theory of Social Structure. New York, NY: Free Press.

Byrne, D. E. (1971). The Attraction Paradigm. New York, NY: Academic Press.

Cannon-Bowers, J. A., Tannenbaum, S. I., Salas, E., \& Volpe, C. E. (1995). Defining competencies and establishing team training requirements. In R. A. Guzzo \& E. Salas (Eds.), Team effectiveness and decision making in organizations (pp.333-380). Hoboken, NJ: John Wiley \& Sons.

Dyck, B., \& Starke, F. A. (1999). The formation of break away organizations: Observations and a process model. Administrative Science Quarterly, 44, 792-823.

Eisenhardt. K. M. \& Bourgeois, L. J. (1988). Politics of strategic decision making in high-velocity environments: Toward a midrange theory. Academy of Management Journal, 31, 737-770.

Ely, R. J., \& Thomas, D. A. (2001). Cultural diversity at work: The effects of diversity perspectives on work group processes and outcomes. Administrative Science Quarterly, 46, 229-273.

George, J. M. (1991). State or trait: Effects of positive mood on prosocial behaviors at work. Journal of Applied Psychology, 76(2), 299-307.

Gibson, C., \& Vermeulen, F. (2003). A healthy divide: Subgroups as a stimulus for team learning behavior. Administrative Science Quarterly, 48, 202-239.

Howell, J. M., \& Avolio, B. J. (1993). Transformational leadership, transactional leadership, locus of control, and support for innovation: Key predictors of consolidatedbusiness-unit performance. Journal of Applied Psychology, 78(6), 891-902.

Janssen, O., Van de Vliert, E., \& Veenstra, C. (1999). How task and person conflict shape the role of positive interdependence in management teams. Journal of Management, 25, 117-142.

Jehn, K. (1995). A multimethod examination of the benefits and detriments of intragroup conflict. Administrative Science Quarterly, 40, 256-282.

Jung, D. I., Chow, C., \& Wu, A. (2003). The role of transformational leadership in enhancing organizational innovation: Hypotheses and some preliminary findings. The Leadership Quarterly, 14, 525-544.

Jobson, J. D. (1992) Applied Multivariate Data Analysis: Categorical and Multivariate Methods, Vol. 2. New York, NY: Springer.

Lau, D. C., \& Murnighan, J. K. (1998). Demographic diversity and faultlines: The compositional dynamics of organizational groups. Academy of Management Review, 23, 325-340.

Lau, D. C., \& Murnighan, J. K. (2005). Interactions within groups and subgroups: The effects of demographic faultlines. Academy of Management Journal, 48(4), 645659.

Li, J. T., \& Hambrick, D. C. (2005). Factional groups: a new vantage on demographic faultlines, conflict, and disintegration in work teams. Academy of Management Journal, 48(5), 794-813.

Lincoln, J. R., \& Miller, J. (1979). Work and Friendship Ties in Organizations: A Comparative Analysis of Relational Networks. Administrative Science Quarterly, 24, 181-199.

Morgan, B. B., Salas, E., \& Glickman, A. S. (1993). An analysis of team evolution and maturation. The Journal of General Psychology, 120, 277-291.

Morrison, D. G. (1967). Measurement problems in cluster analysis. Management Science, 13, 775-780.

Mullen, B (1991). Group composition, salience, and cognitive representations: The phenomenology of being in a group. Journal of Experimental Social Psychology, 27, 297-323.

Mumford, M. D., \& Gustafson, S. B. (1988). Creativity syndrome: Integration, application, and innovation. Psychological Bulletin, 103(1), 27-43. 
Murnighan, J. K., \& Brass, D. J. (1991). Intraorganizational coalitions. Research on Negotiation in Organizations, 3, 283-306.

Pirola-Merlo, A., Hartel, C., Mann, L., \& Hirst, G. (2002). How leaders influence the impact of affective events in team climate and performance in R\&D teams. The Leadership Quarterly, 13, 561-581.

Podsakoff, P. M., \& Organ, D. W. (1986). Self-reports in organizational research: Problems and prospects. Journal of Management, 12, 531-544.

Rousseau, V., Aube, C., \& Savoie, A. (2006). Teamwork behaviors: A review and an integration of frameworks. Small Group Research, 37, 540-570.

Scott, S. G., \& Bruce, R. A. (1994). Determinants of innovative behavior: A path model of individual innovation in the workplace. Academy of Management Journal, 37(3), 580-607.

Sharma, S. (1996) Applied Multivariate Techniques. New York, NY: Wiley.

Siegel, S. M., \& Kaemmerer, W. F. (1978). Measuring the perceived support for innovation in organizations. Journal of Applied Psychology, 63(5), 553-562.

Smith-Jentsch, K., Salas, E., \& Brannick, M. T. (2001). To transfer or not to transfer? Investigating the combined effects of trainee characteristics, team leader support, and team climate. Journal of Applied Psychology, 86(2), 279292.

Spreitzer, G. M., Cohon, S. G., \& Ledford, G. E. (1999). Developing effective self-managing work teams in service organizations. Group \& Organization Management, 24, 340-366.

Stasser, G., Taylor, L. A., \& Hanna, C. (1989). Information sampling in structured and unstructured discussions of three- and sixperson groups. Journal of Personality and Social Psychology, 57, 67-78.

Stevens, M. J., \& Campion, M. A. (1994). The knowledge, skill, and ability requirements for teamwork: Implications for human resource management. Journal of Management, 20, 503-530.

Tagga, S., \& Brown, T. C. (2001). Problem-solving team behaviors: Developing and validation of BOS and a hierarchical factor structure. Small Group Research, 32, 698-726.

Tagga, S., \& Seijts, G. H. (2003). Leader and staff roleefficacy as antecedents of collective efficacy and team performance. Human Performance, 16, 131-156.

Tajfel, H. (1978). The achievement of group differentiation. In H. Tajfel (ed.), Differentiation Between Social Groups (pp.483-507). London: Academic Press.
Tasa, K., Taggar, S., \& Seijts, G. H. (2007). The development of collective efficacy in teams: A multilevel and longitudinal perspective. Journal of Applied Psychology, 92(1), 17-27.

Thatcher, S. M., Jehn, K. A., \& Zanutto, E. (2003). Cracks in diversity research: The effects of diversity faultlines on conflict and performance. Group Decision and Negotiation, 12, 217-241.

Tjosvold, D. (1998). Cooperative and competitive goal approach to conflict: Accomplishments and challenges. Applied Psychology: An International Review, 47, 285-342.

Trezzini, B. (2006). Probing the group faultine concept: an evaluation of measures of patterned multi-dimensional group diversity. Quality and Quantity, 42, 339-368.

Turner, J. C. (1982). Towards a cognitive redefinition of the social group. In H. Tajfel (ed.), Social Identity and Intergroup Relations (pp.15-40). Cambridge, England: Cambridge University Press.

Turner, J. C. (1987). Rediscovering the Social Group: A Self-Categorization Theory. Oxford, England: Basil Blackwell.

Walsh, J. P. (1988). Selectivity and selective perception: An investigation of managers' belief structures and information processing. Academy of Management Journal, 31, 873-896.

West, M. A. (1990). The social psychology of innovation in groups. In M. A. West \& J. L. Farr (eds.) Innovation and Creativity at Work: Psychological and Organizational Strategies (pp.309-333). Chichester: Wiley.

West, M. A. (2002). Sparkling fountains or stagnant ponds: An integrative model of creativity and innovation implementation in workgroups. Applied Psychology: An International Review, 51, 355-387.

West, M. A., Borrill, C. S., Dawson, J. F., Brodbeck, F., Shapiro, D. A., \& Haward, B. (2003). Leadership clarity and team innovation in health care. The Leadership Quarterly, 14, 393-410.

West, M. A. \& Farr, J. L. (1989). Innovation at work: Psychological perspectives. Social Behaviour, 4, 15-30.

Wittenbaum, G. M., \& Stasser, G. (1996). Management of informationin small groups. In J. L. Nye \& A. M. Brower (eds.), What's Social about Social Cognition? Research on Socially Shared Cognition in Small Groups (pp.3-28). Thousand Oaks, CA: Sage.

Van der Vegt, G. S., \& Janssen, O. (2003). Joint impact of interdependence and group diversity on innovation. Journal of Management, 29, 729-751.

Zanutto, E. L., Bezrukova, K., \& Jehn, K. A. (2010). Revisiting faultline conceptualization: Measuring faultline strength and distance. Quality and Quantity, 45, 701-714. 